\title{
Exploration of Teaching Reform of Water Engineering Construction Courses Based on BIM Technology in China
}

\author{
Chao Liu \\ School of Environmental and Municipal Engineering \\ Qingdao University of Technology \\ Qingdao, China
}

\author{
Binjie Qian \\ School of Environmental and Municipal Engineering \\ Qingdao University of Technology \\ Qingdao, China
}

\author{
Liyuan Wang \\ School of Environmental and Municipal Engineering \\ Qingdao University of Technology \\ Qingdao, China \\ Zhiqiang Liu* \\ School of Environmental and Municipal Engineering \\ Qingdao University of Technology \\ Qingdao, China
}

\begin{abstract}
Water engineering construction course is a comprehensively and practically compulsory course for student majored in Water Supply and Sewerage Engineering. It is a subject worth exploring and researching how to improve the teaching effect and efficiency of water engineering construction course. This article introduces the BIM technology and its development trend in China. By expounding the application of BIM technology in water engineering construction, it provides a new idea for the teaching reform of "Water Engineering Construction" course. Because of the visual and simulated features of BIM technology, it overcomes the shortcomings of the traditional teaching boring, making the teaching of water engineering construction become straightforward and interesting, which is of great significance to the students' learning and ability cultivation. However, how to combine the BIM technology and water engineering construction course effectively needs further exploration and research.
\end{abstract}

Keywords-BIM; Reform in Education; Water Engineering Construction; Application

Course of water engineering construction is a compulsory course of water supply and sewerage engineering, which tightly integrates the theoretical work with practical application. The course mainly introduces some common construction techniques, construction organization as well as management problems that may encounter during water engineering construction project. This course will enable students to comprehensively understand and master the essential techniques for the construction of water supply and sewerage engineering. Students can design structure for water engineering that can be practically used with consideration of construction requirements and improve their aptitude for designing. Students can also learn to distinguish and apply the proper materials and mechanical equipment in water supply and sewerage engineering. In addition, students will acquaint the basic principal of constructional organization and management in water supply and sewerage engineering; they can choose the proper constructional scheme under different constructional conditions. With the benefit from this course, students can cultivate and improve the skills to solve practical problems with appropriate theories, and have a profound foundation to engage in designing, construction, operational management, scientific research, and other works after their graduation.

From the point of view of employment, the knowledge of engineering construction is often indispensable, but it is difficult for students to consolidate the knowledge in the classroom and transform into the ability to solve the problem of professional engineering, which makes some students play a passive role in employment [1]. How to improve the teaching method of water engineering construction has become an essential problem. With the advent of BIM technology, the Architecture, Engineering and Construction (AEC) industry will have a profound technical revolution, and also provide a new prospect of the reformation in teaching the course of water engineering construction.

\section{INTRODUCTION OF BIM}

Building Information Modeling (BIM) originated in the United States and was first introduced by Dr. Chuck Eastman of the Georgia Institute of Technology in 1975 [2]. BIM is a multidimensional model information integration technology developed on the basis of Computer Aided Design (CAD) and other technologies. It is a digital bearing and visual expression of the physical characteristics and functional characteristics of construction engineering. It is a shared knowledge resource of related information of engineering projects, which is useful in the whole life cycle of buildings.

The core concept of BIM is the complete description of the engineering object. The data, process, and resources in different stages of the construction project life cycle can be commonly used by all participants in the construction project to solve the problem of consistency and global sharing of information [3]. It has five characteristics: visualization, coordination, simulation, optimization, and plotting [4]. In all phases of the life cycle of a construction project, BIM greatly 
enhances the mobility of information and enables engineering and management personnel to have an accurate and intuitive understanding of building information. Moreover, it provides a reliable basis for the decision making of all participating parties.

As a new information technology, BIM has gained widespread attention in the industry and will certainly greatly promote the transformation of the mode of production in the field of architecture. BIM has been widely used in a number of countries or regions, many of which have legislation to require construction projects must use BIM, for example, United States, United Kingdom, Singapore, Japan, Korea, Hong Kong, and Taiwan. The development of BIM has received the great attention of Chinese government. All relevant departments and local governments have issued BIM policies one after another. BIM gradually adopted by domestic architectural design, construction, consulting management and other businesses and owners agree and embark on the implementation. BIM application promotion trend has been irresistible.

\section{APPLICATION OF BIM IN WATER PROJECT CONSTRUCTION}

\section{A. Application of BIM in Earth and Rock Engineering}

Earth and rock engineering is one of the major projects in the water engineering construction, and has the characteristics of large quantity, wide range, heavy labor, and difficult construction. For example, in some large scale wastewater treatment projects, the earthwork construction can reach hundreds of thousands to million cubic meters in the field leveling and excavation of large foundation pit. Based on the site overall modeling by using BIM technology, making plan to achieve the pre-control of construction scheme. It can greatly reduce the number of earthwork shipment by using BIM technology. Through reasonable design optimization, the amount of filling and excavation of earthwork is controlled to ensure the quality of the project, and the cost is also reduced.

\section{B. Application of BIM in Site Layout}

If a project has synchronized construction of multiple buildings, it is one of the major problems that how to layout the construction site. By using BIM, the technicians can virtually construct all the objects in construction sites, such as large machinery, transportation channel, material storage yard, and gates, to make construction information display more comprehensive and visualized. And then BIM techniques optimize the layout by roaming and simulating the installation and removal time to effectively prevent the occurrence of secondary handling and accidents. That improves work efficiency and reduces the management difficulty. It is also great significance to guide the temporary hydropower arrangement by using BIM model. The common issue of the traditional temporary hydropower layout is that the pipelines are messy and relocated many times; the installation is unstable, which affects the safety on the site and uneven ground. Using BIM model for temporary hydropower layout planning can achieve the same model and site to enhance the appearance of the construction site.

\section{Application of BIM in Pipeline Optimization}

Water projects often encounter many problems, such as types of pipelines, dense, complex, and so on. Through the integration of various professional BIM models, the spatial conflict and analysis of the integrated model are carried out. According to the principle of collision inspection and pipeline prioritization, professional BIM models, such as water supply, drainage, Heating, Ventilation and Air Conditioning (HVAC), and electrical systems, are fully adjusted. Pipeline optimization not only considers the model itself, but also takes into account the site installation and maintenance space, hanger installation, etc., to achieve adjusted zero collision. The application of BIM technology optimizes the layout of the pipeline to ensure the precise layout of the pipeline, which reduces the waste of artificial materials in the construction phase, the construction cost, and the project time.

\section{Application of BIM in Processing Simulation}

By using 3D visual simulation, it can reflect the construction process flow directly and accurately, and ensure the correct transmission of information to the construction and the management side. Analysis of key processes, designers can demonstrate the feasibility of the program, selection and optimization. By modeling the construction process, designers and constructors can avoid the awkward situations in which the word is not understood. This will greatly enhance the efficiency of communication between the two sides. Integrating the actual progress parameters into the BIM model results in a 4D construction schedule model.

Using the simulation of 4D construction progress, designers can visually check the rationality of the logical relationship between the process and the construction contents, as well as any omission in the construction contents. At the same time, according to the needs of the progress of contrast, it improves the management efficiency in construction progress management.

\section{E. Application of BIM on the Spot}

BIM based on site integration is the combination of BIM model and actual construction site. Using the 3D printing technology to form solid models, dynamic templates, animations, replaced traditional two dimensional drawings to guide the construction site. The benefits are intuitive and easy, to avoid rework due to misreading of drawings. At the same time saving time to find information, reducing the site management staff. The staff checks the construction site through the BIM model, which can find and correct errors. The staff will integrate the BIM model of the project with some technologies, such as laser scanning, mobile communications, Internet of Things and the Internet technology. Use the integrated model to guide, record, track and analyze all kinds of construction site activities, to maximize the construction efficiency.

\section{F. Application of BIM in Preform Processing Technology}

As an important manifestation of construction capability and efficiency of preform processing technology, BIM has gradually attracted the attention of enterprises. Mechanical and electrical installation of the main components can be used BIM software for splitting. First, make prefabricated drawings and 
components list of materials. Then all pipes and fittings numbered according to the requirements of the installation sequence on site. The final processing plant for the prefabrication of components and field assembly type construction. The field assembly type construction not only overcomes the harsh environment of traditional construction work, but also reduces the safety accidents on the construction site and the processing site. It has a great effect on shortening the construction time and improving the quality of the project.

\section{G. Application of BIM in Management of Construction}

Based on BIM's construction project management, through the control and management of progress, cost, quality and safety, managers can better achieve the optimal allocation of production elements and dynamic control. Managers combine the construction plan with the BIM model to get the amount of work at any point in time and in the time frame. Therefore, managers can effectively guide the management staff to allocate workload. At the same time, managers can make timely decisions by comparing the actual workload, and improve project duration compliance. In engineering cost management, the use of BIM technology can greatly improve the efficiency and accuracy of engineering calculation, to achieve cost management standardization and refinement. It is helpful for managers to timely adjust the decision making and control direction. The site staff through the mobile site collecting or PC side to records of quality and safety issues, the data released to the BIM system in real time, so the project managers can understand the construction site problems in time, to avoid quality and safety risks. Through the accumulation of data, management analysis of quality and safety problems of multiple parts, in the construction process of deployment, check the key parts and optimize the resources. During the construction process, staff combined the BIM model with the management system to keep the BIM model information constantly updated, which will provide greater convenience and benefit for the construction management.

\section{TEACHING EXPLORATION OF BIM TECHNOLOGY IN WATER ENGINEERING CONSTRUCTION COURSE}

Talents in the water supply and sewerage engineering in addition to having basic knowledge and professional theoretical knowledge, but also need to have engineering related knowledge and extended knowledge. For application oriented colleges and universities, it is more application oriented in engineering technology. It is mainly reflected in the development of the industry and the advancement of science and technology in the field of extended knowledge [5]. It is worth discussing and researching how to fully apply BIM technology to the teaching of water engineering construction course.

Teaching materials are the basis for students' learning and teachers' teaching, and good teaching materials can improve teaching quality effectively. The design theory and construction technology of water supply and sewerage engineering have far exceeded the update pace of the teaching materials. The current teaching materials have some limitations, and the new specifications in the construction of water supply and sewerage are not revised in time. The description is also not enough of new materials, new methods and new technology, so it is difficult to meet the teaching of project related knowledge and extension of knowledge need. It is conducive to solve the problem of combining BIM and water engineering construction course teaching by rewriting the textbook water engineering construction, revising related content, adding the application of BIM technology in water engineering construction and application cases of BIM.

In the traditional teaching mode, students feel that the acquired knowledge is boring and static. Nowadays, the introduction of multimedia teaching has effectively improved this situation, but there is still a high demand for students' ability of imagination and understanding. Visualization is the most prominent feature of BIM technology. The visualization of BIM transforms buildings and components from the previous line drawings into three dimensional physical graphics. Relying on the engineering model of BIM, textbooks intuitively can be transformed into a vivid and concrete form, and stimulate students to learn the passion of the water construction course. At the same time, it can strengthen the level of auxiliary education, such as taking multimedia courseware, construction animation, site pictures and other forms to enhance students' perceptual knowledge. The coordination of BIM can solve the collision between various professions. Teachers can make students aware of the importance of the ability to coordinate cooperation among professions through practical cases. The water engineering construction class based on BIM technology is straightforward, vivid and interesting, which is of great significance to students' learning and ability cultivation.

Water engineering construction teaching based on BIM technology is not only applicable to classroom teaching, but also to practical teaching. Generally, there are fewer opportunities for practical teaching provided by colleges and universities. Internships are often due to a short time, the number of more, to be safe, financial considerations, and it is difficult to ensure the quality of internships, so practice is generally difficult to complete the intended teaching purposes. Teaching model based on BIM technology and video help to teach construction technology without going to the site to visit, safe and reliable. This teaching model can effectively promote the effectiveness of course teaching and improve students' curriculum experience.

Network learning is a good learning method, it breaks through the traditional space time constraints because of extremely rich learning resources on the Internet. Network learning is beneficial to give full play to the talents of students, improving the students' independent learning ability and cooperative ability. But the online resources are so complicated that it is hard to comb for students. Teachers can give students corresponding guidance, and teach them how to select information. Online courses are required for teaching in the information age [6]. Teachers can design online courses for water engineering construction courses. In order to meet the students' self-study after class, teaching resources of online courses should include handouts, video courses, exercises, questions, etc. The combination of classroom teaching, online teaching and practice teaching can help to develop students' ability of independent learning, collaborative innovation, 
comprehensive utilization of knowledge, and engineering practice.

\section{CONCLUSION}

BIM technology has become a real demand for information technology in the construction industry. It will bring a great change to the domestic construction industry, when BIM technology meets the special needs of the domestic construction market. Water engineering construction course is rich in content, comprehensive and practical and other characteristics. It is currently teaching obstacles to transform knowledge into ability how to provide effective water construction technology demonstration and intuitive practice teaching environment. BIM technology with visualization and simulation features will help to solve this problem. However, it also requires the common discussion and research by the majority of teachers how to effectively combine the BIM technology with the water engineering construction courses.

\section{REFERENCES}

[1] Z.Jing. S.Cao. Z.Wang. S.Lin. Z.Wang. "Teaching Exploration on Construction Courses of Water supply and Sewerage Engineering In Chinese [J],” University Education, 2015, (2), pp. 167168.

[2] Eastman, C., Teicholz, P., Sacks, R. and Liston, K., BIM Handbook:A Guide to Building Information Modeling for Owners, Managers, Designers, Engineers and Contractors., published: March 31, 2008 , publisher: John Wiley\&Sons Inc., Chapter 1, pp.vii, 1314, 285286.

[3] BIM Implementation Guide In China Municipal Design Industry In Chinese [Z]. China Inestigation \& Design, 2014, (4), pp. 7.

[4] Guanpei He. B.General theory of BIM In Chinese, China Building Industry Press, Beijing, China, 2011.

[5] F.Cui. X.Zhang. N.Gao. Z.Zhang. W.Li. G.Li. J.Zhang. "Water supply and drainage science and engineering (water supply and sewerage engineering) professional construction and development In Chinese [J]," Water Supply and Sewerage Engineering, 2013, vol. 39,(4), pp.13.

[6] J.Wang. H.Li. X.Ding. "Promote BIM teaching In Chinese [C]", National Building Department of Building Digital Technology Teaching Symposium and Digital Building Design International Symposium in 2014, 2014. 